\title{
(Zn,Cu)O Films by Atomic Layer Deposition - Structural, Optical and Electric Properties
}

\author{
M.I. ŁukASiEWicz ${ }^{a}$, B.S. WitkOWski ${ }^{a}$, Ł. WAChNicki ${ }^{a}$, K. KOPAlko ${ }^{a}$, S. Gieraltowska ${ }^{a}$,

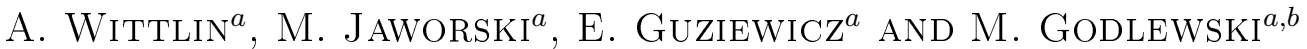 \\ ${ }^{a}$ Institute of Physics, Polish Academy of Sciences, al. Lotników 32/46, 02-668 Warsaw, Poland \\ ${ }^{b}$ Dept. of Mathematics and Natural Sciences College of Science, Cardinal S. Wyszyński University \\ Dewajtis 5, 01-815 Warsaw, Poland
}

\begin{abstract}
$\mathrm{ZnCuO}$ thin films have been deposited on silicon, glass and quartz substrates by atomic layer deposition method, using reactive organic precursors of zinc and copper. As zinc and copper precursors we applied diethylzinc and copper(II) acetyloacetonate. Structural, electrical and optical properties of the obtained $\mathrm{ZnCuO} \mathrm{layers} \mathrm{are}$ discussed based on the results of scanning electron microscopy, energy dispersive spectroscopy, X-ray diffraction, atomic force microscopy, the Hall effect and photoluminescence investigations.
\end{abstract}

PACS: 68.55.Ln, 68.55.Nq, 78.66.Hf, 81.15.Kk

\section{Introduction}

Several potential applications of $\mathrm{ZnO}$ for novel optical devices as, for instance blue light emitters, lasers devices or UV sensors [1] were proposed. In addition, $\mathrm{ZnO}$ doped with transition metal $(\mathrm{TM}=\mathrm{Co}, \mathrm{Cu}, \mathrm{Mn}, \ldots)$ ions is intensively studied for spintronics applications [2]. A theoretical prediction by Dietl et al. [2] suggested that room temperature ferromagnetism (RT FM) should exist in heavily $p$-type doped alloys of $\mathrm{ZnMnO} . \mathrm{Cu}^{+}$can be used as an additional $p$-type dopant into naturally $n$-type $\mathrm{ZnO}$ samples to obtain ferromagnetic $\mathrm{ZnCuO}$ films [3-5]. Even in studies where RT FM is reported, the effect of carrier type on the ferromagnetic properties is unclear [5]. So the research on high-quality (Zn,TM)O alloys systems is becoming fairly important.

\section{Experimental}

All discussed $\mathrm{ZnCuO}$ samples were grown between $200{ }^{\circ} \mathrm{C}$ and $300^{\circ} \mathrm{C}$ by the atomic layer deposition (ALD) technique using the F-120 Microchemistry reactor and double exchange reactions. In our experiments we applied diethylzinc (DEZn) as a zinc precursor, copper (II) acetylacetonate $\left(\mathrm{Cu}(\mathrm{acac})_{2}\right)$ as a copper precursor, and deionized water as an oxygen precursor. These highly reactive precursors are sequentially introduced to the growth chamber, so they meet only at a surface of a grown film. The use of these precursors allows us the significant reduction of a growth temperature to $300{ }^{\circ} \mathrm{C}$ and below, which proved to be very important for the growth of uniform films of ( $\mathrm{Zn}, \mathrm{TM}) \mathrm{O}$ [6]. $\mathrm{ZnCuO}$ samples were grown with different $\mathrm{Zn}$-to- $\mathrm{Cu}$ ratios of the ALD cycles, which turned out to be crucial to obtain uniform $\mathrm{ZnCuO}$ layers, as already indicated in Refs. [6, 7].

Different substrates were used depending on experiment requirements - Si for structural and optical investigations, quartz or glass for electrical measurements. The surface morphology was analyzed from the results of atomic force microscopy (AFM, Bruker Dimension Icon) investigations, using the PeakForce Tapping and silicon nitride probes with sharp tips (a tip radius: $2 \mathrm{~nm}$ ). RT Hall effect measurements were performed using the RH2035 PhysTech GmbH system equipped with a $B=0.426 \mathrm{~T}$ permanent magnet. Electrical measurements were done in the van der Pauw geometry using e-beam evaporated $\mathrm{Ti} / \mathrm{Au}$ as an ohmic contact to $\mathrm{Zn}$ $\mathrm{CuO}$. SEM measurements were performed using scanning electron microscope Hitachi SU_70 equipped with a GATAN MonoCL System.

The structure and the crystallographic orientation of $\mathrm{ZnCuO}$ layers were measured by the $\mathrm{X}$-ray diffraction (XRD) using the X'Pert MPD diffractometer in a full angular range. Quality of the layers was investigated by a high resolution X'Pert MRD diffractometer equipped with the X-ray mirror, a two-bounce monochromator at the incident beam and a Pixcel detector at the diffracted beam.

\section{Results}

The results of XRD measurements are shown in Fig. 1. We optimized the ALD cycles (ratio of $\mathrm{ZnO}$ to $\mathrm{CuO}$ ALD cycles) in order to obtain depth and in-plane homogeneous $\mathrm{ZnCuO}$ films. The $\mathrm{X}$-ray diffraction measurements of $\mathrm{ZnCuO}$ films deposited on silicon substrate showed 


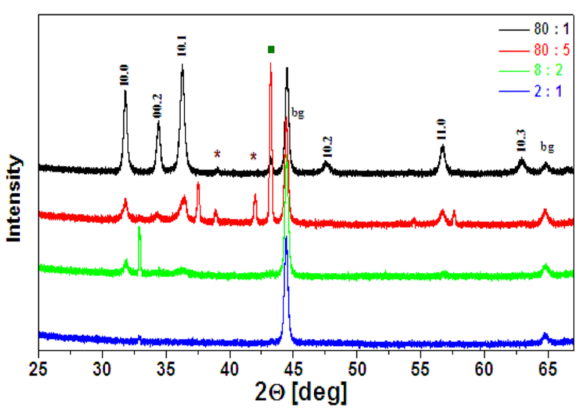

Fig. 1. $2 \theta$ XRD spectra of the polycrystalline $\mathrm{ZnCuO}$ samples grown at $250{ }^{\circ} \mathrm{C}$ with different ratio of $\mathrm{ZnO}$ to $\mathrm{CuO}$ ALD cycles. The peaks $(*)$ belong to the $\mathrm{CuO}$ phase and the one marked with ( $)$ is due to $\mathrm{Cu}$ metal inclusions.

that the $\mathrm{Cu}$ doping (for $\mathrm{Cu}$ doping concentration below $10 \%$ ) does not change the wurtzite structure of $\mathrm{ZnO}$.

The XRD investigations indicate however that foreign phases and metal inclusions are formed even for relatively low $\mathrm{Cu}$ fractions in $\mathrm{ZnCuO}$. At growth temperature $250^{\circ} \mathrm{C}$ and $\mathrm{Cu}$ concentration of $3 \%$ the films show segregation of a second phase (the XRD peaks marked with ${ }^{*}$ ) due to $\mathrm{CuO}[3,8]$ and of (the XRD peaks marked with -) $\mathrm{Cu}$ metal inclusions. When the $\mathrm{Cu}$ concentration is higher than $20 \%$ we observed amorphous structure of the films obtained.

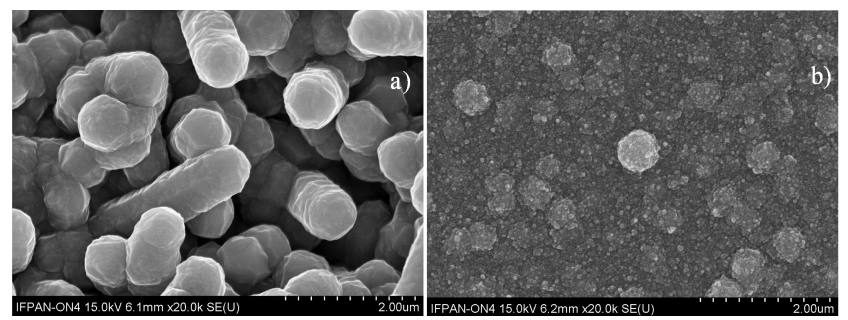

Fig. 2. SEM images of the ALD grown $\mathrm{ZnCuO}$ films on silicon substrate for samples with different ratios of $\mathrm{ZnO}$ to $\mathrm{CuO}$ ALD cycles: (a) 80:1 and (b) 8:2.

The surface morphology of $\mathrm{ZnCuO}$ films was investigated with the scanning electron microscopy (SEM) and atomic force microscopy (AFM). Figure 2 shows the SEM images of the $\mathrm{ZnCuO}$ films grown at $250^{\circ} \mathrm{C}$ by the ALD with (a) eighty to one and (b) eight to two ratios of $\mathrm{ZnO}$ to $\mathrm{CuO}$ ALD cycles. Flakes-like or nanorods structure of $\mathrm{ZnCuO}$ films was often observed for thin films with $\mathrm{Cu}$ concentration above $5 \%$. It turned out that it is by far more difficult (than for $\mathrm{ZnMnO}$ or $\mathrm{ZnCoO}$ ) to find optimal growth conditions to get films of a good structural quality grown in $2 \mathrm{D}$ mode.

Root mean square (RMS) value of roughness of the films ranged between $6 \mathrm{~nm}$ and $25 \mathrm{~nm}$, depending on the $\mathrm{Cu}$ fraction. AFM investigation indicates that roughness of these layers grows with an increase of $\mathrm{Cu}$ concentration in $\mathrm{ZnCuO}$ films (see Fig. 3). Clearly 3D growth

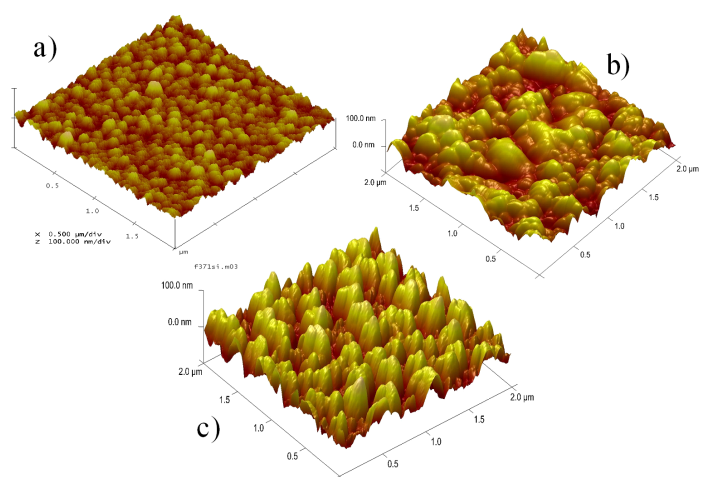

Fig. 3. $\mathrm{AFM}$ images of $\mathrm{ZnCuO}$ films for: (a) $\mathrm{Cu}=$ $1.5 \%(\mathrm{RMS}-7.5 \mathrm{~nm}),(\mathrm{b}) \mathrm{Cu}=10 \%(\mathrm{RMS}-22 \mathrm{~nm})$, and (c) $\mathrm{Cu}=25 \%$ (RMS $-25 \mathrm{~nm}$ ).

mode dominates, as also observed in the SEM investigations. We do not observe correlations between a growth temperature and layers thickness (number of the ALD cycles) and roughness of $\mathrm{ZnCuO}$ films. We observed such correlation for $\mathrm{ZnCoO}$ films, as reported in our previous work [7].

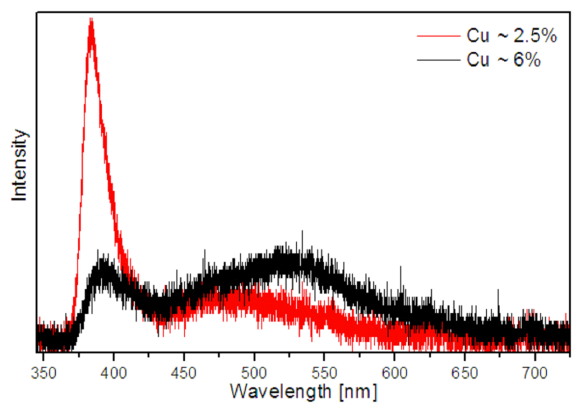

Fig. 4. Room temperature PL spectra for $\mathrm{ZnCuO}$ thin film grown at $250{ }^{\circ} \mathrm{C}$. We show the data for the as-grown samples with two different $\mathrm{Cu}$ concentrations.

The room temperature PL spectra of the $\mathrm{ZnCuO}$ samples are shown in Fig. 4. The $382 \mathrm{~nm}$ peak is assigned to the $\mathrm{ZnO}$ near-band edge transition. The PL spectra show that introduction of $\mathrm{Cu}$ to $\mathrm{ZnO}$ quenches visible PL around $382 \mathrm{~nm}$. This effect is clearly $\mathrm{Cu}$ related. In turn, the broad and intense green emission at about $520 \mathrm{~nm}$ rises in intensity with $\mathrm{Cu}$ concentration. Likely this PL band is associated with $\mathrm{Cu}$ doping, since this PL increases with $\mathrm{Cu}$ concentration in $\mathrm{ZnCuO}$.

The Hall-effect measurements show that most of the $\mathrm{ZnCuO}$ films are of $n$-type with carrier concentration up to $4 \times 10^{19} \mathrm{~cm}^{-3}$. Surprisingly $n$ concentration does not depend on $\mathrm{Cu}$ concentration and on growth temperature.

\section{Conclusions}

$\mathrm{ZnCuO}$ films were grown at low temperature by the ALD method using organic zinc and copper precursors. 
The highest $\mathrm{Cu}$ concentration achieved in the present work was about $25 \%$. Most of the films studied show $n$-type conductivity. Formation of foreign phases and inclusions of $\mathrm{Cu}$ metal are detected for the films with and increased $\mathrm{Cu}$ concentration.

\section{Acknowledgments}

The research was supported by the EU within the European Regional Development Fund through grant Innovative Economy (POIG.01.01.02-00-008/08).

\section{References}

[1] U. Ozgur, Ya.I. Alivov, C. Liu, A. Teke, M.A. Reshchikov, S. Dogan, V. Avrutin, S.-J. Cho, H. Morkoc, J. Appl. Phys. 98, 041301 (2005).

[2] T. Dietl, H. Ohno, F. Matsukura, J. Cibert, D. Ferrand, Science 287, 1019 (2000).
[3] C. Sudakar, J.S. Thakur, G. Lawes, R. Naik, V.M. Naik, Phys. Rev. B 75, 054423 (2007).

[4] D. Chakraborti, J. Narayan, J.T. Prater, Appl. Phys. Lett. 90, 062504 (2007).

[5] D.B. Buchholz, R.P.E. Chang, J.H. Song, J.B. Ketterson, Appl. Phys. Lett. 87, 082504 (2005).

[6] M.I. Łukasiewicz, B. Witkowski, M. Godlewski, E. Guziewicz, M. Sawicki, W. Paszkowicz, R. Jakieła, T.A. Krajewski, G. Łuka, Phys. Status Solidi B 247, 1666 (2010).

[7] M. Łukasiewicz, A. Wójcik, M. Godlewski, E. Guziewicz, R. Jakieła, M. Kiecana, M. Sawicki, Acta Phys. Pol. A 114, 1235 (2008).

[8] H.-T. Lin, T.-S. Chin, J.-C. Shih, S.-H. Lin, T.-M. Hong, R.-T. Huang, F.-R. Chen, J.-J. Kai, Appl. Phys. Lett. 85, 621 (2004). 